Regina Suplicy VIANNA ${ }^{1}$ Pedro Primo BOMBONATO ${ }^{1}$

Correspondência para:

Rua São Francisco, 25, Cotia, SP, Brasil, CEP 06708-380, telefone (11) 4612-6032 ou 9505-4615

e-mail reginasvianna@tattwayoga.com.br

Recebido para publicação: 16/05/2005 Aprovado para publicação: 17/08/2007

\title{
Estudo histométrico do ligamento cruzado cranial de cão (Canis familiaris)
}

1 - Departamento de Cirurgia da Faculdade de Medicina Veterinária e Zootecnia da Universidade de São Paulo, São Paulo-SP

\section{Resumo}

Estudo-se o ligamento cruzado cranial de 30 cães, quantificando a proporção de fibras colágenas, reticulares e elásticas em 3 regiões, correspondentes à sua origem no fêmur, ao fragmento médio proximal e à inserção na tíbia. Os dados coletados foram confrontados com idade e peso dos animais. A média da proporção de fibras colágenas foi de $43 \%$; fibras reticulares $16,28 \%$ e fibras elásticas $7,35 \%$. Não existiu diferença significativa entre as 3 regiões ou entre estas regiões e a média do ligamento como um todo, quando confrontado os dados dos grupos separados por peso, mas ao separá-los conforme a idade observamos diferença muito significativa na proporção de fibras reticulares, a qual sofreu decréscimo progressivo diretamente proporcional com o avançar da idade.

\section{Introdução}

A articulação fêmoro-tíbio-patelar é uma das junturas mais complexas, pois não se beneficia de nenhuma congruência de suas superfícies articulares, encontrando sua estabilidade basicamente nos meios de união e seus anexos. Dentre estes temos os ligamentos cruzados, duas faixas esbranquiçadas e arredondadas, situadas na fossa intercondilar, com função essencial, pois formam um verdadeiro pivô axial regulando o afrontamento e deslocamento dos côndilos femorais e tibiais. O ligamento cruzado cranial auxilia na prevenção da hiper-extensão do joelho, da rotação excessiva da tíbia em direção à face medial do fêmur, assim como evita o deslizamento cranial do "platô" da tíbia em relação ao fêmur, conhecido como "movimento de gaveta", presente nos animais portadores de ruptura do ligamento cruzado cranial, reforçando sua importância na estática articular. $1,2,3,4,5,6,7,8,9,10,11,12,13,14,15$

A ruptura de ligamento cruzado, especialmente o cranial, é um problema clínico há muito tempo observado na prática veterinária. ${ }^{1}$ Primeiramente descrita por Carlin (1926 apud ARNOCZKY, 1988, p. 71), não encontramos mais citações até 1953 quando foi sugerida a utilização da fascia lata como transplante do ligamento cruzado cranial de cão (Paatsama, 1953 apud JOHNSON; JOHNSON, 1993), o que já havia sido feito no homem (Hey Groves, 1920 apud McCURNIN; PEARSON; WASS, 1971, p. 1517). Várias técnicas cirúrgicas foram desenvolvidas para devolver a estabilidade à articulação, seja intra-articular $9,16,17$ ou extra-articular, utilizando materiais sintéticos ou mesmo membranas biológicas, mas com resultados bastante controvertidos entre os autores De Angelis (1970 apud McCURNIN; PEARSON; WASS, 1971, p. 1518) D'Oliveira ${ }^{18}$, Dupuis et al. ${ }^{16} \mathrm{e}$ Mccurnin; Pearson e Wass?.

Vasseur, Arnoczky e Lau ${ }^{13}$ notaram que o ligamento cruzado cranial é mais acometido por ruptura do que o caudal, sendo que esta doença inicia-se mais cedo e progride mais rápido em cães de grande porte, enquanto que animais de menor porte apresentam maior incidência de ruptura do ligamento cruzado cranial com idade mais avançada. ${ }^{8,9,14,19,20,21}$

Entretanto a literatura sobre a composição estrutural do ligamento cruzado cranial, particularmente nos cães, não tem 
merecido atenção como têm as descrições das lesões e diferentes possibilidades de tratamento. Assim sendo, propusemo-nos a estudar a constituição do ponto de vista histométrico, caracterizando a proporcionalidade dos tipos de fibras que o compõem e suas relações com peso e idade dos animais.

\section{Material e Método}

O ligamento cruzado cranial foi coletado de 30 cães com idade, peso e sexo determinados. Cada ligamento foi cortado em três fragmentos eqüitativos, correspondente à região de origem no fêmur, ao fragmento médio e o de inserção na tíbia, processados segundo técnica histológica convencional. Cortes de 5 micrometros foram corados pelas técnicas de Picro-sírius, para quantificar colágeno, de Gordon, para reticulina e do Tricômio de Verhoeff, para as fibras elásticas.

Os dados coletados foram adquiridos com o auxílio do microscópio óptico Axioscop Zeiss ${ }^{\circledR}$ e os resultados foram analisados em um microcomputador com programa de morfometria específico KS 400-ZEISS ${ }^{\circledR}$, obedecendo à seqüência descrita:

1) Captação da imagem; 2) Calibração do equipamento; 3) Engenharia da imagem; 4) Identificação da freqüência da cor do tecido estudado por campo; 5) Binarização das imagens; 6) Mensuração dos campos; 7) Listagem dos dados.

Inicialmente os cães foram separados em grupos conforme o peso (P1 - animais com peso até 15 quilogramas; P2 - animais com peso superior a 15 quilogramas) e idade (I1 - animais com idade até 2 anos; I2 animais com idade acima de $2 \mathrm{e} / \mathrm{ou}$ até 9 anos; I3 - animais com idade a partir de 10 anos). Finalmente confrontamos os dados dos animais segundo as variáveis peso e idade.

Os dados adquiridos foram tratados estatisticamente com auxílio do programa INSTAT em computador PC compatível com ambiente Windows. Utilizamos o teste " $\mathrm{t}$ " de Student, o de análise de variância de médias (ANOVA), teste de Correlação de Pearson e teste de Bartlett, com nível de significância de $5 \%$.

\section{Resultados}

Observamos que o ligamento cruzado cranial é composto por feixes espessos de fibras de colágeno entremeadas por fibras elásticas e reticulares. O tecido conjuntivo comporta-se envolvendo todo o ligamento à semelhança de uma bainha, emitindo para seu interior feixes de fibras que delimitam lojas menores constituídas por fibrilas, com arranjos em diferentes direções (Figura 1).

A proporção de fibras de colágeno variou de 3,70 a $84,33 \%$, com média de $45 \pm$ 15 (Figura 2). O índice de correlação da proporção de fibras colágenas entre o ligamento direito e esquerdo foi sempre positivo e de média intensidade, segundo o peso corporal ou idade dos animais, porém, entre as três regiões de um mesmo ligamento este índice foi baixo (Tabela 1).

A proporção de fibras elásticas variou de 1,02 a $26,53 \%$, com média de $7,55 \% \pm$
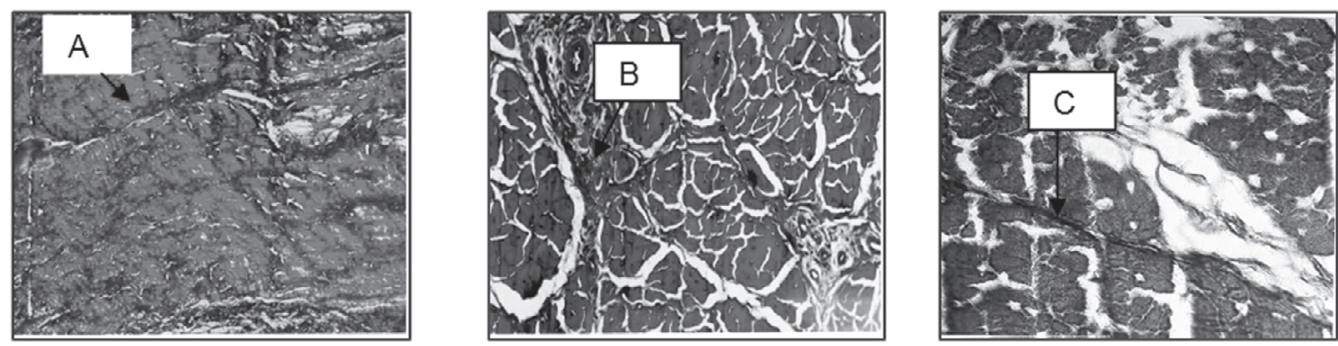

Figura 1 - Fotomicrografia do ligamento cruzado cranial de cão (aumento 400x) evidenciando quantidades diferentes de fibras colágenas (A), elásticas (B) e reticulares (C), coradas respectivamente com Picrosirius, Verhoeff e Reticulina de Gordon 


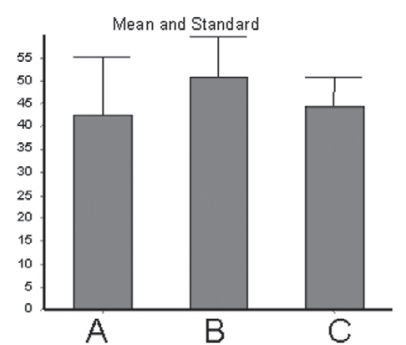

Figura 2 - Média e erro padrão da proporção de fibras colágenas no ligamento cruzado cranial de cão (A - idade até dois anos; B - idade acima de dois e até nove anos e C - idade a partir de 10 anos)

4,23\% (Figura 3). O índice de correlação foi alto entre os ligamentos direito e esquerdo, exceto para animais com peso acima de 15 quilogramas e idade superior a dois anos, que apresentaram um índice baixo e negativo (Tabela 1). Ao se analisar o índice entre as três regiões, este se mostrou alto para a maioria dos grupos, exceto para animais com peso acima de 15 quilogramas e idade de dois até nove anos ou a partir de 10 anos, onde o índice de correlação entre as regiões foi baixo, apresentando valores positivos e

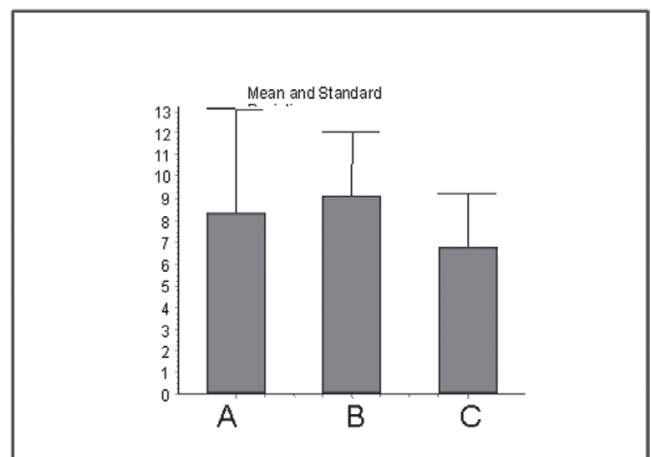

Figura 3 - Média e erro padrão de fibras elásticas no ligamento cruzado cranial de cão (A - idade até dois anos; B - idade acima de dois e até nove anos e $\mathrm{C}$ - idade a partir de 10 anos)

negativos, respectivamente.

A proporção de fibras reticulares variou de 2,19 a 55,71\%, com média de $16,68 \% \pm 7,50 \%$ (Figura 4). A distribuição das correlações de fibras reticulares entre os lados direito e esquerdo ou entre as três regiões analisadas no ligamento cruzado cranial de cães não apresentou tendências marcantes de predomínio, tendo sido encontrados valores de " $r$ " positivos e negativos, com intensidade que variaram de tendência à nulidade até alta (Tabela 1).

Tabela I - Índice de correlação entre a proporção de fibras elásticas, colágenas e reticulares nos ligamento cruzado cranial direito e esquerdo de cão, São Paulo - 2004

\begin{tabular}{lcccccc}
\hline & El./Col: $\mathbf{d}$ & El./ Col: $\mathbf{e}$ & El./ Ret: $\mathbf{d}$ & El./ Ret: $\mathrm{e}$ & Ret./Col.d & Ret /Col.:e \\
\hline GERAL & 0,26 & 0,10 & 0,43 & 0,35 & 0,03 & $-0,07$ \\
P 1 & 0,63 & 0,38 & 0,15 & 0,35 & 0,06 & 0,24 \\
P 2 & $-0,05$ & $-0,02$ & 0,61 & 0,24 & $-0,01$ & $-0,54$ \\
I 1 & 0,55 & 0,24 & 0,40 & 0,23 & 0,11 & $-0,03$ \\
I 2 & $-0,10$ & $-0,18$ & 0,59 & 0,01 & 0,40 & 0,10 \\
I 3 & 0,65 & $-0,03$ & 0,22 & 0,73 & 0,24 & 0,05 \\
P 1 I 1 & 0,77 & 0,49 & 0,31 & 0,57 & 0,67 & 0,78 \\
P 1 I 3 & 0,70 & 0,59 & $-0,88$ & 0,42 & $-0,66$ & 0,34 \\
P 2 I 1 & $-0,04$ & $-0,03$ & 0,83 & $-0,13$ & $-0,39$ & $-0,90$ \\
P 2 I 2 & $-0,09$ & $-0,09$ & 0,64 & 0,34 & 0,54 & $-0,39$ \\
P 2 I 3 & $-0,19$ & $-0,62$ & 0,78 & 0,86 & $-0,40$ & $-0,70$ \\
\hline
\end{tabular}

E1./Col. d. - Fibras elásticas e colágenas do ligamento cruzado cranial direito

E1./ Ret. d. - Fibras elásticas e reticulares do ligamento cruzado cranial direito

Ret./Col. d.-Fibras reticulares e colág enas do ligamento cruzado cranial direito

E1./ Col. e. - Fibras elásticas e colágenas do ligamento cruzado cranial esquerdo

E1./ Ret. e.- Fibras elásticas e reticulares do ligamento cruzado cranial esquerdo

Ret./Col.e. - Fibras reticulares e colágenas do lig am ento cruzado cranial esquerdo

P 1 - animais com peso até 15 quilogramas

P 2 - - animais com peso acima de 15 quilogramas

I 1 - animais com idade até dois anos

I 2 - animais com idade acima de dois e/ou até nove anos

I 3 - animais com idade acima de10 anos 
Nos agrupamentos de fibras reticulares observamos diferença entre as médias do ligamento cruzado cranial como

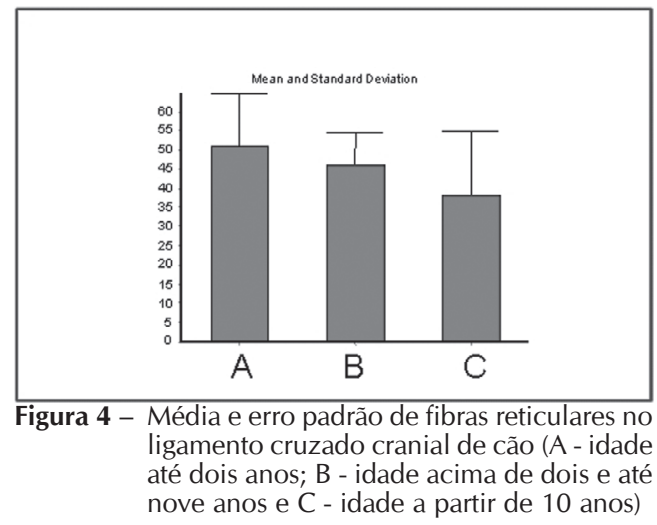

um todo de forma progressiva e diretamente proporcional com o avançar da idade, havendo uma redução idadedependente entre os grupos de idade até dois anos (coluna A, Figura 4) e o grupo com idade a partir de 10 anos (coluna C, Figura 4).

Ao confrontarmos as proporções dos diferentes tipos de fibras, notamos que a quantidade de fibras elásticas é diretamente proporcional a quantidade de fibras colágenas, com correlação média e alta para os animais do grupo com peso menor que 15 quilogramas e inversamente proporcional, mas com índice de correlação muito baixo, para os animais do grupo com peso maior que 15 quilogramas.

A correlação entre a quantidade de fibras reticulares e colágenas é muito baixa quando separamos os animais somente segundo o peso ou a idade, mas ao confrontarmos peso e idade, os animais com peso menor que 15 quilogramas e idade até dois anos apresentam um alto índice de correlação entre a proporção destas fibras e quando o peso é maior de 15 quilogramas, o índice de correlação varia de médio e alto, porém sempre inversamente proporcional. Ainda notamos que, genericamente quanto maior a quantidade de fibras reticulares, menor é a quantidade de fibras colágenas, exceção feito para o grupo de animais com peso abaixo de 15 quilogramas e idade até dois anos, cuja correlação é alta e diretamente proporcional.

A proporção entre as fibras elásticas e reticulares é diretamente proporcional e com maior intensidade na medida em que se aumenta o peso ou a idade (Tabela 1).

O teste de Bartlett foi utilizado para a caracterização estatística do tipo de distribuição que os valores encontrados apresentam e serviu, ao indicar a distribuição homocedântica da amostra, para referendar a utilização de outros testes da normalidade e distribuição gaussiana, aplicados aos dados compilados, tais como a ANOVA e teste de correlação de Pearson. Do ponto de vista biológico esse teste indicou que os nossos resultados distribuem-se em conformidade a uma curva normal bicaudal.

A ANOVA mostrou a existência de emparelhamento positivo entre os parâmetros do ligamento cruzado como um todo com os parâmetros das três regiões e entre as regiões de origem no fêmur, segmento médio proximal e inserção na tíbia. Não existe diferença significativa entre estas médias quando analisadas para as fibras colágenas $(\mathrm{P}=0,15 ; \mathrm{F}=1,81 /$ Fcrítico $=5,30)$, fibras elásticas $(\mathrm{P}=0,22 ; \mathrm{F}=1.46 / \mathrm{F}$ crítico $=28,82)$ e fibras reticulares $(\mathrm{P}=0,79 ; \mathrm{F}=$ $0,34 /$ Fcrítico $=6,12$ ).

A ANOVA aplicada na proporção de fibras colágenas de animais de diferentes idades indicou a existência de variação entre a média dos animais com idade até dois anos (coluna A, Figura 2) com os do grupo de idade acima de dois e/ou até nove anos (coluna B, Figuras $1,2,3)$.

\section{Discussão}

Observamos que o ligamento cruzado cranial é constituído por feixes paralelos e espessos de fibras de colágeno, distribuídos longitudinalmente, com alguns fibroblastos entremeados no tecido conjuntivo elástico e reticular, os quais percorrem da bainha para os feixes, subdividindo-os em várias lojas menores, se mostrando em orientações diversas, às vezes transversos ao longo do eixo axial do 
ligamento, mas também obliquamente em algumas regiões, em concordância com vários autores, 4,7,13,14,19,20,21 tendo $\mathrm{O}$ comprimento e calibre do ligamento cruzado cranial variando significativamente com o peso corporal ${ }^{13,14,15}$.

Alguns autores observaram perda na organização estrutural de fibras e feixes primários de colágeno na histologia dos ligamentos naturalmente rompidos. Afirmaram ainda que a afecção iniciava-se mais cedo e progredia mais rápido em cães de grande porte, enquanto que animais menores apresentavam maior incidência da ruptura do ligamento cruzado cranial com idade mais avançada. ${ }^{13,19}$ Relatam ainda a existência de diminuição da resistência do ligamento cruzado cranial em animais com idade mais avançada, sendo mais acentuada naqueles com peso maior. ${ }^{7,13,19,20}$

A constituição do ligamento mostrou grande variedade na proporção de fibras colágenas, elásticas e reticulares, ora predomina uma ora não existe predomínio, e por isso temos resultados positivos e negativos, com intensidades diferentes quando analisamos a correlação métrica entre as proporções dos três tipos de fibras. Esta ausência de padrão na proporção, quantidade e de correlação entre as fibras pode ser um fator predisponente para ruptura do ligamento cruzado cranial.

Ao distribuir os animais em grupos, não encontramos diferenças significativas na proporção de nenhum dos tipos de fibras quando correlacionada apenas quanto à diferença de peso, mas sim uma diminuição significativa da proporção de fibras reticulares com o aumento da idade, o que não se coaduna com relatos da literatura. ${ }^{14}$

Como as fibras reticulares são as responsáveis por conter as fibrilas do colágeno agrupadas, a sua diminuição pode permitir um desarranjo entre as fibras colágenas e interferir na dinâmica do ligamento, levando a degeneração progressiva destas fibras, favorecendo assim a ruptura do ligamento em animais com idade mais avançada.

Notamos ainda que a proporção de fibras elásticas é diretamente proporcional a quantidade de fibras colágenas para animais com peso menor que 15 quilogramas e inversamente proporcional para os animais de peso superior a 15 quilogramas. Este fato pode justificar a diminuição da resistência à tração, observada por outros autores ${ }^{2}$, com a incidência de ruptura deste ligamento mais precocemente em animais mais pesados, embora o índice de correlação observado por nós tenha sido muito baixo.

Embora alguns autores afirmem que o ligamento cruzado cranial se rompe mais freqüentemente no seu terço médio, Paatsama (1953 apud JOHNSON; JOHNSON, 1993), Vasseur, Arnoczky e Lau ${ }^{13}$, Neurath e Stoff ${ }^{17}$ e Stocchi et al. ${ }^{21}$, sugerindo que a pressão que um ligamento exerce sobre o outro pode reduzir o suprimento sanguíneo, não conseguimos detectar diferenças significativas entre as três regiões do ligamento cruzado cranial quanto à proporção de fibras colágenas, elásticas ou reticulares que sugerisse o embasamento morfométrico para tal afirmação.

Estudos morfométricos do ligamento cruzado cranial em diferentes espécies, com medição do diâmetro de suas fibrilas, ${ }^{17,22}$ e quantificação de dois tipos de fibras de colágeno deste ligamento em humanos ${ }^{21}$ são relatados, porém, nenhum deles comentou sobre possíveis modificações quanto as diferentes regiões do ligamento.

Não foi encontrada, na literatura específica ou mesmo correlata, nenhuma indicação quantitativa sobre a composição do ligamento cruzado cranial confrontando as diferentes regiões do referido ligamento, nem mesmo em outras espécies de animais ou com utilização de outras metodologias morfométricas. Este fato, no nosso entendimento, reforça a necessidade de aprofundamento e estabelecimento de outros trabalhos enfocando os aspectos morfométricos não só do ligamento cruzado cranial em cães, mas também de outras estruturas ligamentares e em outras espécies animais. 


\section{Conclusões}

Este estudo permite-nos concluir que:

1.O ligamento cruzado cranial apresenta significativa variação na quantidade de fibras colágenas, reticulares, não apresentando um padrão quantitativo definido.

2.Existe correlação de média a alta intensidade entre as proporções de fibras colágenas do membro direito e esquerdo, porém ela é baixa quando confrontada as três regiões (origem, média e inserção) entre si.

3.Existe correlação de alta intensidade na proporção de fibras elásticas entre os ligamentos direito e esquerdo, exceto para animais com peso acima de 15 quilogramas e idade superior a dois anos, que foi baixa.

4.Não há nenhum predomínio na proporção de fibras reticulares entre os ligamentos direito e esquerdo e entre as três regiões do ligamento, porém a análise de variância das médias entre os animais de diferentes idades indica uma redução progressiva na proporção de fibras reticulares do ligamento com o aumento da idade.

5.A proporção de fibras elásticas é diretamente proporcional à quantidade de fibras colágenas nos animais com peso menor que 15 quilogramas e inversamente proporcional para os animais com peso maior que 15 quilogramas, porém com índice de correlação muito baixo.

6.O índice de correlação entre a quantidade de fibras reticulares com as colágenas é baixo quando os animais são agrupados isoladamente pelo peso ou idade, porém quando analisamos as variáveis peso e idade em conjunto, quanto maior é a quantidade de fibras reticulares, menor é a quantidade de fibras colágenas, exceto para animais com peso abaixo de 15 quilogramas e idade até dois anos, onde a correlação é alta e diretamente proporcional.

7.Não existiu diferença significativa na média entre as três regiões (origem, media e inserção do ligamento) ou entre estas regiões e a média do ligamento como um todo ao agrupar os animais com diferentes peso e idade.

\section{Histhometric study of the dog cranial cruciate ligament (Canis familiaris)}

\section{Abstract}

The cranial cruciate ligament was studied in 30 dogs, where proportion of fibers collagen, elastic and reticulin were measured in 3 segments: femoral insertion, median segment and tibial insertion. The results were analyzed with confrontation of age and body weight. The data were statistically analyzed by means of ANOVA, "t"Student and correlation test. The results draw to the following conclusions: 1- ) The mean of fibers collagen proportion was $43 \%$, elastic fibers was $7,35 \%$ and and reticulin fibers proportion was 16, 28\%. 2 -) There was no difference between the 3 regions, 3.) By confrontation among reticulin fibers proportion measurements with the age, a high intensity correlation was observed, as older $\mathrm{dog}$, less reticulin fibers proportion was found. 4 -) There was no significant differences among the ligament fibers proportion data concerning the body weight.
Key words:

Cranial cruciate ligament. Dog.

Collagen and reticular fibers. Histometric study.

\section{Referências}

1 ADAMS, D.R. Canine anatomy. Ames: The lowa State University Press, 1986.

2 ARNOCZKY, S. P.; MARSHAL, J. L. The cruciate ligaments of the canine stifle. An anatomical and functional analysis. American Journal of Veterinary Research, v. 38, n. 1, p. 1807-1814, 1977.

3 CHIARUGI, G. Anatomia dell'uomo. 7a. ed., Milano: Societa Editrice libraria, 1948. v. 1, p. 809.

4 DENOIX, J. M. Elements d'anatomic fonctionnelle comparré du ligament croise cranial. Recueil de 
Medicine Veterinaire, v. 165, n. 1, p. 19-25, 1989.

5 ELLEMBERGER, W.; BAUM, H. Handbuch der vergleichenden anatomie der haustiere. Berlin: Springer-Verlag, 1985. p. 184.

6 EVANS, H. E.; CHRISTENSEN, G. C. Ligaments of stifle joint. In: Miller's Anatomy of the dog. 2 ed. Philadelphia: W.B. Saunders, 1979. p. 263.

7 HEFRON, L. E.; CAMPBELL, J. R. Morphology, histology and functional anatomy of the canine cranial cruciate ligament. Veterinary Record, v. 102, n. 1, p. 280-283, 1978

8 JOHNSON, J. M.; JOHNSON, A. L. Cranial cruciate ligament rupture - Pathogenesis, diagnosis and postoperative rehabilitation. Veterinary Clinics of North America: Small Animal Practice, v. 23, n. 4, p. $717-$ 733, 1993.

9 MCCURNIN, D. M.; PEARSON, P. T.; WASS, W. M. Clinical and pathological evaluation of ruptured cranial cruciate ligament repair in the dog. American Journal Veterinary Research, v. 32, n. 10, p. 1517-1523, 1971.

10 NICKHEL, R. et al. The anatomy of the domestic animal. Berlin: Paul Parey, 1986. v. 1, p. 206-207.

11 SCHWARZE, E.; SCHRÖEDER, L. Compêndio de anatomia veterinária. Zaragoza: Acribia, 1970. Tomo 1.

12 TESTUT, I.; JACOB, O. Anatomia topográfica. 7. ed. Torino: Editrice Torinese, 1943. v. 2.

13 VASSEUR, P. B.; ARNOCZKY, S. P.; LAU, R. E., Correlative biomechanical and histologic study of the cranial cruciate ligament in dogs. American Journal Veterinary Research, v. 46, n. 9, p. 1842-1854, 1985.

14 VIANNA, R. S. Estudo morfométrico do ligamento cruzado cranial de cão. 1997. Dissertação (Mestrado) -
Faculdade de Medicina Veterinária e Zootecnia, Universidade de São Paulo, São Paulo, 1997.

15 VIANNA, R. S. Ultra-sonografia Ortopédica. In: CARVALHO, C. F. Ultra-sonografia em pequenos animais. 1. ed. São Paulo: Roca, 2004. p 246-247.

16 DUPUIS, J. et al. Evaluation of the lateral collateral ligament after fibular head transposition in dogs. Veterinary Surgery, v. 23, n. 1, p. 456-465, 1995.

17 NEURATH, M.; STOFF, E. Fascicular and subfascicular architecture of the cruciate ligament. Unfallchirurgie, v. 18, n. 3, p. 125-132, 1992.

18 D'OLIVEIRA, K. S. Reparação cirúrgica extraarticular da ruptura do ligamento cruzado cranial de cão (Canis familiaris) com centro frênico heterólogo preservado em glicerina. 1999. Dissertação (Mestrado) - Faculdade de Medicina Veterinária e Zootecnia, Universidade de São Paulo, São Paulo, 1999.

19 ARNOCZKY, S. P. The cruciate ligaments: the enigma of the canine stifle. Journal of Small Animal Practice, v. 29, p. 71-90, 1988.

20 MOSS, E. W.; FERGUSON, T. H. Tensile strength of the cranial cruciate ligament in cattle. American Journal Veterinary Research, v. 41, n. 9, p. 1408-1411, 1980.

21 STROCCHI, R. et al. The human anterior cruciate ligament: histological and ultra-structural observations. Journal of Anatomy, v. 180, p. 515-519, 1992.

22 HART, R. A.; WOO, S. L.; NEWTON, P. O. Ultra structural morphometry of anterior cruciate and medial collateral ligaments: an experimental study in rabbits. Journal of Orthopedic Research, v. 10, n. 1, p. 96-103, 1992.

23 MONTES, G. S. Structural biology of the fibbers of the collagenous and elastic systems. Cell Biology International, v. 20, n. 1, p. 15-27, 1996. 